\title{
Co-existence of History of Mathematics and Education of Mathematics
}

\author{
Saied seyed agha Banihashemi* \\ School of inter national realtions of MOFA IRAN, Tehran Iran \\ *Corresponding author: Ihusaied2001@yahoo.com
}

Received June 03, 2014; Revised July 10, 2014; Accepted July 27, 2015

\begin{abstract}
Both history of mathematics and education of mathematics are old subjects. This question arises whether these two important subjects can help each other or not. Unfortunately this idea divided mathematics society into two groups one have the idea that History of Mathematics can help education of mathematics and the other group have idea that not only history of mathematics can not help education of mathematics but also it make some confusion. In this article I am going to make some comparison and take some conclusion that history of mathematics can make education of mathematics so active and interesting.
\end{abstract}

Keywords: history of amtematics, education of mathematics, innovation

Cite This Article: Saied seyed agha Banihashemi, "Co-existence of History of Mathematics and Education of Mathematics.” American Journal of Educational Research, vol. 2, no. 8 (2014): 592-594. doi: 10.12691/education-2-8-5.

\section{Introduction}

We know that history of mathematics and education of mathematics both is two branch of mathematics science. A lot of Research scholar in word working and doing reasearch in this two branch of mathematics. Question is here that can these two group of researcher can help each other? Reality is that I n society of mathematics two idea are there on group which had idea that history of mathematics can help teacher of mathematics a lot and in next section we give some example to prove this idea in other group people have idea that history of mathematics can not help education of mathematics and we give some point of their view. In the end in comparison of this idea I give my conclusion.

\section{On Application of History of Mathematics in Education of Mathematics}

\subsection{Application of History of Mathematics}

What is application of history of mathematics? We know that researcher duty in history of mathematics is to read mathematical manuscript, understand those things and rewrite them in new mathematics so which this work need expert people which know old language and mathematics and some idea about society of that time. For that reason society of historian of mathematics in every where is small in number (compare to other branches of mathematics). And from this small society few people teach mathematics or thinking about education of mathematics now usually \%25 of papres in international conference of education of mathematics are about history of mathematics or its application [ ].
So joint work of historian of mathematics and education of mathematics can prepare material for teacher of mathematics and in higschools and. Universities. So when teacher came to know that time is suitable they can explain about history of geometry, algebra, analysis, graph theory, and so on spicily when students feel tired in classes and still we have time to end of classes. By explain of history of number student not only dose not feel tired but also waiting for next classes to know more about numbers.

Students by knowing life history of, paytogorian, Tales, Aryabahtyia, Ramurajan, Kharasmi, Kashani, Taragellia, .....

Will come to know that science is works of all civilization so they have respect for other nation young people of each civilization by history of mathematics will come to know that his old generation also had contribution on construction of science so they will find confidence.

One of goal of education of mathematics is to teach better and better. in the mathematical manuscripts we can find methods on mathematical operation s which if we teach in this manner student can do faster and understand better two example are as follow :

\section{a) Doing multipication by Kashani method}

Sutdent with Kashani method are more comfortable [4].

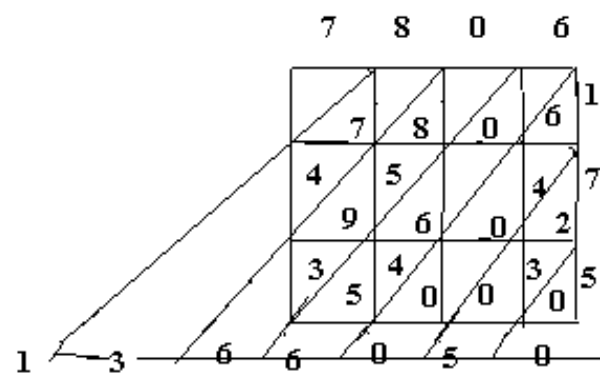

Figure 1. 
For better understanding of solving equations Islamic mathematicians use visualization for example Kharazmi use geometry to explanation of procedure. He wants to solve $x^{2}+c=b x$. He explain the system of solving in this manner: [2]

"Let the side of square $\mathrm{ABCD}$ is answer of equation. In direction of $\mathrm{AB}$ and $\mathrm{BC}$ we choose $D^{\prime}, C^{\prime}$ since $A D^{\prime}=B C^{\prime}=b x$. The points E,F is middle of $A D^{\prime}, B C^{\prime}$. Then me make square GFIH on GF so we have :

$$
\begin{aligned}
& G F=G E-F E=\frac{b}{2}-x \\
& \text { 1) } S_{G F I H}=|G F|^{2}=\left(\frac{b}{2}-x\right)^{2}
\end{aligned}
$$$$
\text { So }
$$

if we can calculate area of this square on basis of b,c with squaring we have value of $\mathrm{x}$ from figure it is clear that

2) $S_{G F I H}=S_{G E C^{\prime} J}-\left(S_{F E C^{\prime} D^{\prime}}+S_{H I D^{\prime} J}\right)$

From other side

$\mathrm{HI}=\mathrm{FD}=\mathrm{GF}, \mathrm{HJ}=\mathrm{DC}=\mathrm{x}$

3) $[(H I=F D=G F) \wedge(H J=D C=x)]$

$\Rightarrow S_{H I D^{\prime} J}=S_{D C E F}$

From 2 and 3

$$
\begin{aligned}
& S_{G F I H}=S_{G E C^{\prime} D}-\left(S_{F E C^{\prime} D}+S_{D C E F}\right) \\
& \text { 4) }=S_{G E C^{\prime} J}-S_{D C C^{\prime} D^{\prime}} \\
& \text { 5) } S_{G E C^{\prime} J}=|G E|^{2}=\left(\frac{b}{2}\right)^{2} \\
& \text { 6) } \begin{aligned}
& S_{G E C^{\prime} J}=S_{A B C^{\prime} D^{\prime}}-S_{A B C D} \\
= & \overline{A D^{\prime}} \cdot \overline{A B}-|A B|^{2}=b x-x^{2}=c
\end{aligned}
\end{aligned}
$$

From $3,4,5,6$ we have

7) $S_{G F I H}=S_{G E C^{\prime} J}-S_{D C C^{\prime} D^{\prime}}=\left(\frac{b}{2}\right)^{2}-c$

From 1 and 7 we have :$$
\begin{aligned}
& \left(\frac{b}{2}-x\right)^{2}=\left(\frac{b}{2}\right)^{2}-c \Rightarrow \frac{b}{2}-x=\sqrt{\left(\frac{b}{2}\right)^{2}-c} \\
& \Rightarrow x=\frac{b}{2}-\sqrt{\left(\frac{b}{2}\right)^{2}-c}
\end{aligned}
$$

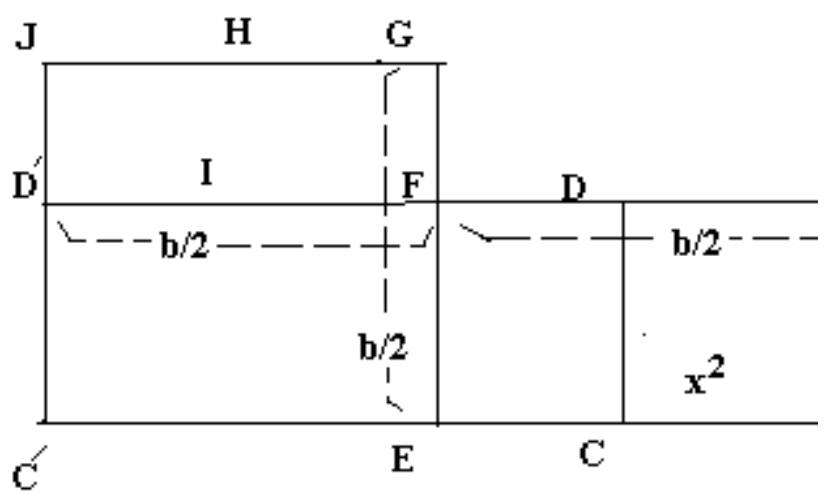

Figure 2.

Another application of history of mathematics is using correct name for correct formula in the below you can see a list of formula which named nucorrct.

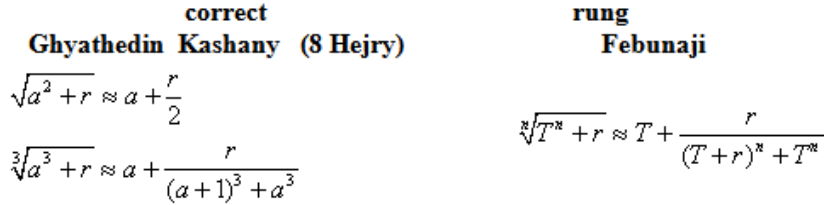

Mahvira900) A.D(

$$
C_{r}^{n}=\frac{n !}{(n-r) ! r !} \text { Herigeone (1634) }
$$

Aryabatai(499 A.D

(Pell(1685)

$N x^{2}+1=y^{2}$

and so on. [1] and [3].

In history of mathematics we have a lot of problem in different level which can improve mathematical thinking of student consider to following example: Example -1Abolvafa Bozjani one of the famous mathematician of 328 of Hejry (940. A.D) he had very nice books which all translated in English and French. In his book with the name geometry operation there is very beautiful problem can make student interest and better thinking as follow:

"How we can make with three equal square a new square"

Let the student thinks for few minutes and compare their work with Bozjani method

Solution: Let a,b,c three equal square we divide two of them into two parts by diameter as follow:

\section{Now the Mathematicians who are not Agreeing with History of Mathematics Claim that}
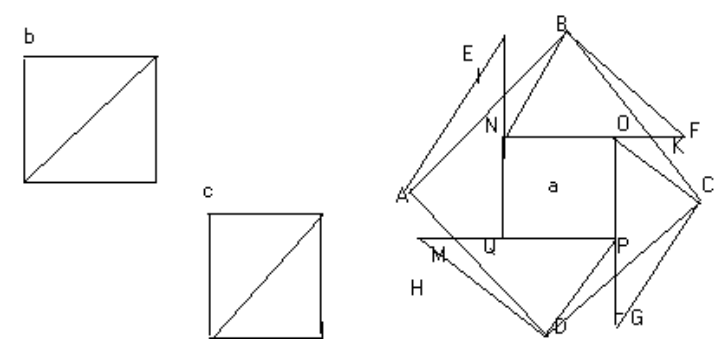

Figure 3.

Mathematical text for usage of teachers are not enough and if some history of mathematics book is there they do not know how to use them. Some problem in history of mathematics makes confusion for student like squaring the circle:

\section{Squaring Circle by Ramrajan Method}

Squaring the circle is another problem which different civilization was interested

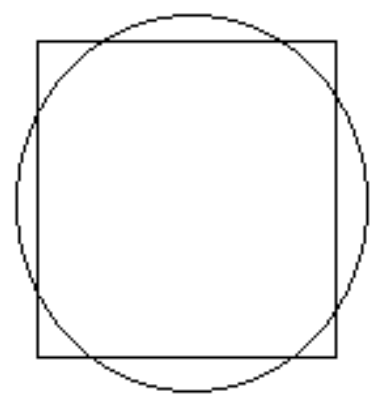

Figure 4. 
It is seems very simple according to idea of students but when they start to calculate they will see it is not possible because

Area of a circle with diameter 1 is equal to

$$
\begin{aligned}
& A=\pi R^{2} \text { ifR }=1 \Rightarrow A=\pi \\
& A=x^{2} \Rightarrow \pi=x^{2} \Rightarrow x=\sqrt{\pi}
\end{aligned}
$$

Since $\pi$ is unknown never we can find x. But different mathematician from different civilization tried to find a system to solve this problem [1].

In comparison of these wives we can conclude that positive points for co-existence of history of mathematics and education of mathematics are so much than negative point I will suggest that all those studying mathematics to be teacher must pass a course on history of mathematics.

\section{References}

[1] Indian mathematics Dr. Balchandra 1994 Janna Deep publication.

[2] Episodesin the mathematicsof medieval Islam J.L Berggren.

[3] The historical roots of elementary mathematics -Lucas N.H.BuntPhilip.S.Jones -Jack D.Bedient - Dover-x.

[4] Kashane Nameh -Ghorbani Abolghasem- Nasher publication 1998-tehran Iran. 